\title{
Protagonismo do estudante universitário na prevenção da infecção pelo Trichomonas vaginalis
}

\author{
Protagonism of university student in preventing Trichomonas vaginalis infection \\ El papel de los estudiantes universitarios en la prevención de la infección por Trichomonas vaginalis
}

Recebido: 22/05/2021 | Revisado: 30/05/2021 | Aceito: 04/06/2021 | Publicado: 18/06/2021

Clênio Silva da Cruz

ORCID: https://orcid.org/0000-0002-6690-2117

Universidade Federal de Pernambuco, Brasil

E-mail: cleniobep@gmail.com

Paulo Henrique Valença Nunes

ORCID: https://orcid.org/0000-0003-4048-580X

Universidade Federal de Pernambuco, Brasil

E-mail: p_henriqui@hotmail.com

Wilza Wanessa Melo França

ORCID: https://orcid.org/0000-0001-9530-8371

Universidade Federal de Pernambuco, Brasil

E-mail: wilza.franca@ufpe.br

João Victor Ritinto da Rocha

ORCID: https://orcid.org/0000-0003-4336-4448

Universidade Federal de Pernambuco, Brasil

E-mail: joao.ritinto@ufpe.br

José Josenildo Batista

ORCID: https://orcid.org/0000-0002-9871-7194

Universidade Federal de Pernambuco, Brasil

E-mail: josenildobatista06@gmail.com

Thierry Wesley de Albuquerque Aguiar

ORCID: https://orcid.org/0000-0001-6104-1808

Universidade Federal de Pernambuco, Brasil

E-mail: Thierry.wesley@ufpe.br

Adriana Maria da Silva

ORCID: https://orcid.org/0000-0001-9942-5372

Universidade Federal de Pernambuco, Brasil

E-mail: adrianams98@yahoo.com

Emily Gabriele Marques Diniz

ORCID: https://orcid.org/0000-0001-6843-2561

Universidade Federal de Pernambuco, Brasil

E-mail: emilygabriele1999@gmail.com

Alcilene de Lima Aires

ORCID: https://orcid.org/0000-0002-4043-3076

Universidade de Pernambuco, Brasil

E-mail: alcileneaires2011@hotmail.com

Leandro Pimentel Cabral

ORCID: https://orcid.org/0000-0002-4094-1345

Universidade Federal de Pernambuco, Brasil

E-mail: cabral.leop@gmail.com

Anekécia Lauro da Silva

ORCID: https://orcid.org/0000-0003-2778-1460 Universidade Federal do Vale do São Francisco, Brasil

E-mail: anekecia.lauro@univasf.edu.br

Hianna Arely Milca Fagundes Silva

ORCID: https://orcid.org/0000-0001-8220-3458

Universidade Federal de Pernambuco, Brasil E-mail: Hiannaamfs@gmail.com

Hallysson Douglas Andrade de Araújo ORCID: https://orcid.org/0000-0001-5150-1655

Universidade Federal de Pernambuco, Brasil E-mail: douglas.ufpe29@gmail.com

Mônica Camelo Pessoa de Azevedo Albuquerque

ORCID: https://orcid.org/0000-0002-2882-6563

Universidade Federal de Pernambuco, Brasil

E-mail: monica.aalbuquerque@ufpe.br

André de Lima Aires

ORCID: https://orcid.org/0000-0001-9283-1466

Universidade Federal de Pernambuco, Brasil E-mail: andre.laires@ufpe.br 


\title{
Resumo
}

Objetivo: Construir conhecimento sobre Trichomonas vaginalis/tricomoníase junto à universitários do sexo masculino das áreas de Ciências Exatas e da Natureza, Tecnologia e Geociências e Informática da Universidade Federal de Pernambuco. Metodologia: Extensão universitária realizada através da Educação em Saúde nos semestres 2017-2019. Foi montado stand com painéis sobre T. vaginalis/tricomoníase e com auxílio de bancadas expostos folders, cartilhas, preservativos, lubrificantes íntimo e material de laboratório para diagnóstico da tricomoníase. Sessenta extensionistas, estudantes de graduação das Ciências Biológicas, Saúde e Médica, atuaram na transmissão e construção do conhecimento. Resultado: As ações educativas alcançaram 3.162 estudantes com idade média entre 19,65-23,05 anos de idade. O diálogo foi consolidado, mas no início alguns demonstraram timidez e no geral, declararam não conhecer às formas de transmissão e tratamento, importância epidemiológica do sexo masculino na manutenção da tricomoníase, além dos agravos à saúde masculina. Nas ações cerca de 3.500 folders sobre T. vaginalis/tricomoníase e 15.000 folhetos/cartilhas sobre HIV/AIDS, sífilis e hepatites virais, além de 25.000 preservativos peniano, 2.000 preservativos vaginal e 40.000 sachês de lubrificante íntimo, foram distribuídos. Conclusão: As ações contribuíram no processo educativo participativo, onde os universitários do sexo masculino atuaram como sujeitos reflexivos e ativos na construção do conhecimento sobre o $T$. vaginalis/tricomoníase e na conquista da autonomia na adoção de prevenção, levando à sustentabilidade da vida sexual saudável e segura. A Universidade é locu estratégico para promover ações inovadoras e transformadoras em Educação em Saúde que favoreçam a formação dos seus estudantes, bem como seu vínculo com a sociedade.

Palavras-chave: Intervenção educacional precoce; Educação em saúde; Tricomoníase; Saúde do estudante.

\begin{abstract}
Objective: To build knowledge about Trichomonas vaginalis/trichomoniasis with male university students in the areas of Exact Sciences and Nature, Technology and Geosciences and Informatics of the Federal University of Pernambuco. Methodology: University Extension carried out through Health Education in the semesters 2017-2019. Was mounted stand with panels on T. vaginalis/trichomoniasis and with the aid of exposed countertops folders, booklets, condoms, intimate lubricants and laboratory material for trichomoniasis diagnosis. Sixty extensionists, undergraduate students of Biological Sciences, Health and Medical worked in the transmission and construction of knowledge. Result: Educational actions reached 3,162 students with mean age between 19-23 years. The dialogue was consolidated but at first some university students showed shyness and in general, declare not knowing the forms of transmission and treatment, the epidemiological importance of male sex in the maintenance of trichomoniasis as well as male health problems. In the actions about 3,500 folders on $T$. vaginalis/trichomoniasis and 15.000 leaflets/booklets on HIV/AIDS, syphilis and viral hepatitis, in addition to 25.000 penile condoms, 2.000 vaginal condoms and 40.000 sachets of intimate lubricant were distributed. Conclusion: The actions contributed to the participatory educational process where male university students acted as reflective and active subjects in the construction of knowledge about T. vaginalis/trichomoniasis and in the achievement of autonomy in the adoption of prevention, leading to the sustainability of healthy and safe sex life. The University is a strategic locu to promote innovative and transformative actions in Health Education that favor the training of its students as well as its link with society.
\end{abstract}

Keywords: Early intervention educational; Health education; Trichomonas infections; Student health.

\section{Resumen}

Objetivo: Construir conocimiento sobre Trichomonas vaginalis/tricomoniasis entre estudiantes varones de las áreas de Ciencias Exactas y Naturales, Tecnología y Geociencias y Informática de la Universidad Federal de Pernambuco. Metodología: Extensión universitaria realizada a través de la Educación para la Salud en los semestres 2017-2019. Se montó un stand con paneles sobre $T$. vaginalis/tricomoniasis y con la ayuda de stands se expusieron folders, cartillas, preservativos, lubricantes íntimos y material de laboratorio para el diagnóstico de la tricomoniasis. Sesenta extensionistas, estudiantes de pregrado de Ciencias Biológicas, Salud y Ciencias Médicas, actuaron en la transmisión y construcción del conocimiento. Resultado: Las acciones educativas alcanzaron a 3.162 estudiantes con una edad media entre 19,65-23,05 años. El diálogo se consolidó, pero al principio algunos alumnos mostraron timidez y, en general, declararon no conocer las formas de transmisión y tratamiento, la importancia epidemiológica del sexo masculino en el mantenimiento de la tricomoniasis, además de los problemas de salud masculinos. En las acciones se distribuyeron unos 3.500 folders sobre $T$. vaginalis/tricomoniasis y 15.000 cartillas sobre el HIV/AIDS, la sífilis y la hepatitis viral, además de 25.000 preservativos para el pene, 2.000 preservativos vaginales y 40.000 sobres de lubricante íntimo. Conclusión: Las acciones contribuyeron al proceso educativo participativo, donde los estudiantes universitarios masculinos actuaron como sujetos reflexivos y activos en la construcción del conocimiento sobre $T$. vaginalis/tricomoniasis y el logro de la autonomía en la adopción de la prevención, lo que lleva a la sostenibilidad de la vida sexual saludable y segura. La Universidad es un lugar estratégico para promover acciones innovadoras y transformadoras en Educación para la Salud que favorezcan la formación de sus estudiantes, así como su vinculación con la sociedad.

Palabras clave: Intervención educativa Precoz; Educación en salud; Tricomoniasis; Salud del estudiante. 


\section{Introdução}

Segundo a Organização Mundial de Saúde (OMS) todos os dias há mais de um milhão de novos casos de Infecções Sexualmente Transmissíveis (IST) curáveis (infecções causadas por Chlamydia trachomatis, Neisseria gonorrhoeae, Treponema pallidum e Trichomonas vaginalis) em todo o mundo, comprometendo especialmente a saúde da população entre 15 a 49 anos de idade (Muzny, 2018; Rowley et al., 2019). Isto representa cerca de 370 milhões de novos casos anuais de clamídia, gonorreia, sífilis e tricomoníase; sendo a tricomoníase, parasitose causada pelo protozoário T. vaginalis, responsável por cerca de 50\% da carga de todas as IST curáveis (Newman et al., 2015; Rowley et al., 2019). No Brasil a prevalência da tricomoníase é estimada entre 10 e $35 \%$ e dois milhões de novos casos são registrados todos os anos, acometendo especialmente jovens das capitais dos estados das regiões Norte e Nordeste (Newman et al., 2015; Ministério da Saúde (BR), 2015).

A tricomoníase é a IST não-viral mais disseminada entre a população sexualmente ativa. No entanto, cerca de $92 \%$ dos casos são diagnosticados em mulheres, uma vez que, comumente a infecção no homem é assintomática (Menezes, Frasson \& Tasca, 2016; Rowley et al., 2019). Frente a condição assintomática do homem, estudos destacam a importância do homem na transmissão e manutenção da cronicidade da tricomoníase na população feminina, pois inadvertidamente, disseminam o protozoário sem saber da sua real condição de saúde. Por outro lado, quando sintomática, a tricomoníase na população masculina pode causar uretrite purulenta abundante e lesões peniana e prostática, que causam desconforto e mal-estar (Schwebke \& Burgess, 2004; Muzny, 2018). O parasita pode se disseminar para a glande e por via ascendente alcançar a bexiga, vesícula seminal e testículos, evoluindo para raras complicações como balanopostite, cistite, prostatite, epididimite, infertilidade masculina e câncer de próstata. Adicionalmente, a tricomoníase é ainda cofator para transmissão do HIV, HPV, herpes, hepatites virais, gonorréia e sífilis, infecções potencialmente fatais (Schwebke \& Burgess, 2004; Newman et al., 2015; Ministério da Saúde (BR), 2015).

A inclusão da dimensão de gênero, a partir do entendimento de que suas relações são importantes no cenário da saúde, foi desencadeada pelo movimento feminista na década de 1960 e sinaliza que nas últimas décadas o gênero passou a representar comportamento importante para implantar e avaliar políticas públicas e auxiliar na redução de desigualdades e vulnerabilidade identificadas socialmente entre gêneros (Pereira, Klein \& Mayer, 2019). Além disto, o entendimento do cuidado para saúde é incorporado, com frequência, à figura da mulher; o homem, em geral, "não foi muito criado para se cuidar" (Separavich \& Canesqui, 2013; Sousa \& Carvalho, 2017). Com o objetivo de transmudar esse cenário, em agosto de 2008, nos marcos dos 20 anos do Sistema Único de Saúde (SUS), através da Secretaria de Atenção à Saúde do Ministério da Saúde foi criada a Política Nacional de Atenção Integral à Saúde do Homem com princípios e diretrizes que inclui o jovem masculino como grupo de risco para exposições às IST ao não adotar com frequência práticas preventivas (Separavich \& Canesqui, 2013). Além disto, incentiva a implantação de ações de promoção, prevenção e tratamento das IST e de mudanças nos paradigmas na percepção do cuidado com a saúde sexual e reprodutiva do jovem masculino (Separavich \& Canesqui, 2013; Ministério da Saúde (BR), 2015; Sousa \& Carvalho, 2017; Pereira, Klein \& Mayer, 2019).

$\mathrm{Na}$ adolescência, fase peculiar de desenvolvimento, o jovem enfrenta toda a sorte de infortúnios de uma sociedade em constante transformação. É uma fase marcada por profundas transformações físicas, psíquicas e sociais, as quais tornam o adolescente mais vulnerável a situações de risco, como violência, abuso de álcool, uso de drogas lícitas e ilícitas e a exposição às IST (Sevalho, 2012; Pereira, Klein \& Mayer, 2019). Alguns estudos destacam que o adolescente masculino universitário apresenta comportamentos de risco para contrair e transmitir IST (Sales et al., 2016; Pereira, Klein \& Mayer, 2019).

A entrada para a universidade oferta a adolescentes, jovens e adultos, formação acadêmica e profissional ao mesmo tempo que permite a transição para um mundo ainda desconhecido e repleto de novas experiências, inclusive sexuais (Chen et al., 2008; Moreira, Dumith \& Paludo, 2018). Adicionalmente, o conhecimento sobre IST e questões relacionadas à saúde 
reprodutiva, por vezes, ainda é incipiente na população universitária (Chen et al., 2008; Moreira, Dumith \& Paludo, 2018). Segundo Moreira e colaboradores (2018), o sexo masculino é vulnerável a exposição e transmissão de IST e, neste cenário as Universidades/Faculdades devem promover a construção do conhecimento relacionado à educação sexual e sexualidade dos seus alunos.

A OMS incentiva estudos do homem numa perspectiva relacional de gênero, aí se destacando a importância na saúde e o comportamento de homens adolescentes, uma vez que essa população influencia diretamente a saúde de mulheres. Ademais, Vilhena (2013) ao estudar a Sexualidade masculina do adolescente destaca que a compreensão de modelos hegemônicos de masculinidade pode favorecer a emergência de ações voltadas à gravidez precoce, à prevenção de IST e à construção de identidades sexuais. Negligenciar a saúde do homem pode acarretar enormes custos para a sociedade. Assim, é fundamental projetos de extensão na Educação em Saúde que privilegie o protagonismo masculino em ações de promoção a sua saúde sexual.

A Educação em Saúde é uma prática social, cujo processo contribui para a formação da consciência crítica das pessoas, a partir de suas realidades, a respeito de seus problemas de saúde e estimula a busca de soluções e organização para a ação individual e coletiva (Falkenberg et al., 2014). No geral, os estudos de educação em saúde frente às IST realizados com adolescentes objetivam ações concentradas no controle e prevenção do HIV e/ou da gravidez não planejada e precoce, e apresentam como população-alvo escolares de ambos os sexos. Assim, a ausência de estudos com estudantes universitários do sexo masculino sobre Educação em Saúde no conhecimento da tricomoníase, o impacto, a dinâmica e a multicausalidade dessa infecção justificam a realização deste estudo, que apresenta como objetivo construir o conhecimento sobre tricomoníase junto a universitários do sexo masculino das áreas de Ciências Exatas e da Natureza, Geociências e Tecnologia e Informática da Universidade Federal de Pernambuco (UFPE) de 2017 até 2019.

\section{Metodologia}

O presente estudo fez parte de um projeto de extensão aprovado pela Pró-reitora de Extensão e Cultura da Universidade Federal de (UFPE) com uma proposta educativa de Educação em Saúde articulado com o Ensino e a Pesquisa. As ações foram planejadas e desenvolvida na Área Acadêmica de Medicina Tropical do Centro de Ciências Médicas da UFPE nos semestres letivos de 2017 até 2019. Trata-se de uma pesquisa-ação com base empírica e abordagem qualitativa. Apesar de assumir diferentes aspectos, a pesquisa-ação nos termos propostos por Thiollent, 1986; Monceau, 2005; Tripp, 2005; Franco, 2005; Franco, 2018 é construída por desenhos de estudos centralizados na produção de conhecimento de forma coletiva e dialógica, articulado com o objeto de estudos na intervenção e transformações de realidades sociais. É importante entender que a pesquisa-ação não é formada apenas pela ação, prática ou participação, mas a ela concerne o desafio de adquirir e/ou ampliar conhecimentos, contribuindo com discussões e reflexões de problemas do cotidiano de diferentes grupos sociais (Corrêa, de Campos \& Almagro, 2018). Há princípios comuns que embasam pesquisas dessa natureza, mas o percurso metodológico não segue um padrão rígido, sendo bastante flexível, incluindo na estrutura de pesquisa pedagógica e educativa em estratégias de Educação em Saúde que objetivam construir conhecimento e estimular a expressão individual na tomada de decisões (Toledo \& Jacobi, 2013; Corrêa, de Campos \& Almagro, 2018).

\section{Etapas do percurso metodológico da ação educativa:}

\section{I - Formação de recursos humanos}

Por seu preceito formativo, a pesquisa-ação possibilita a continua construção da consciência crítica dos participantes, público-alvo e pesquisadores (Tripp, 2005). Neste cenário, sabe-se que os estudantes de graduação estão em processo de 
formação acadêmico-profissional; assim, fez-se necessário planejar e executar capacitação antes de colocá-los em prática nas ações de Educação em Saúde. Logo, construímos grupos de estudo e seminários sobre a biologia do Trichomonas vaginalis, relação parasito hospedeiro e fisiopatogenia da tricomoníase, cenário epidemiológico, atenção à saúde do sexo masculino e estratégias de ensino-aprendizagem em Educação em Saúde. Além de oficinas com pesquisadores da área; incluindo infectologista, microbiologista, epidemiologista e biólogo licenciado. O objetivo foi habilitar os extensionistas para assistir com confiança docente e técnico-cientifica o público-alvo. Os agentes ativos na transmissão e construção do conhecimento sobre tricomoníase foram 60 extensionistas - graduandos em Ciências Biomédicas, Ciências Farmacêuticas, Enfermagem, Odontologia, Nutrição e Medicina da UFPE.

\section{II - Busca por parcerias}

Entramos em contato com gestores das Secretarias Estadual e Municipal de Saúde de Pernambuco e Recife, respectivamente, que gentilmente forneceram preservativos peniano e vaginal e gel lubrificante íntimo, além de folders e cartilhas informativos sobre outras IST.

\section{III - Público-alvo e local e planejamento das ações de Educação em Saúde}

O público-alvo foi formado por universitários do sexo masculino dos cursos das áreas de Ciências Exatas e da Natureza, Geociências e Tecnologia e Informática da UFPE. As ações de Educação em Saúde foram realizadas nos Centros de Ciências Exatas e da Natureza (CCN), Tecnologia e Geociências (CTG) e Informática (CIn) da UFPE. A cada semestre letivo realizamos uma ação em cada Centro, totalizando 18 ações - 6 ações em cada Centro. Cada ação ocorreu em tempo médio de 6 horas. Antes das ações realizamos visitas técnicas nos Centros e/ou Departamentos para selecionar locais estratégicos (intenso fluxo de estudantes) e as ações foram realizadas em áreas abertas próximas às bibliotecas e principais corredores que dão acesso as salas de aula e/ou laboratórios de ensino e pesquisa.

Os alunos foram convidados a participarem da ação educativa. Com o objetivo de privar extensionistas e público-alvo de possíveis constrangimento frente à temática Infecção Sexualmente Transmissível, a ação educativa foi mediada sempre por dois ou três extensionistas e individualmente ou em grupos de dois até cinco universitários. A ação foi sustentada por roda de conversa por se tratar de método de ressonância coletivo que consiste no desenvolvimento de espaços de diálogo, em que os alunos se expressam e, sobretudo escutam os extensionistas, outros alunos e a si mesmos. Assim, objetivamos estimular a autonomia por meio da problematização, da troca de conhecimento e da reflexão através da teoria da aprendizagem significativa. Percurso metodológico em corroboração com Esteves Campos (2020) que reporta a participação coletiva no fortalecimento e indissociabilidade da tríade ensino-pesquisa-extensão. Ademais, segundo (Tripp, 2005; Franco, 2018) a pesquisa-ação tem perfil político-pedagógico, reconhecendo e valorizando a pluralidade de saberes e o contexto de atuação do público-alvo em ações educativas.

\section{IV - Elaboração do material didático}

Como veículo de informação folder e painéis $(\mathrm{n}=10)$ foram elaborados com informações sobre biologia do $T$. vaginalis (morfologia, habitat, transmissão, ciclo de vida) e a epidemiologia, sinais e sintomas, patogênese, diagnóstico, tratamento e profilaxias da tricomoníase. Com os painéis montamos stand e com auxílio de bancadas foram expostos materiais de laboratório empregados na cultura do parasito para seu diagnóstico (padrão-ouro), os folders, preservativos, lubrificantes e cartilhas. 


\section{Resultados e Discussão}

A saúde do homem surge como questão a ser estudada a partir do comportamento de risco adotado pelo próprio, muitas vezes arraigado pelos ditames de uma masculinidade hegemônica imposta socialmente (Separavich \& Canesqui, 2013; Sousa \& Carvalho, 2017; Pereira, Klein \& Mayer, 2019). No presente estudo as ações de Educação em Saúde foram aplicadas juntos à universitários do sexo masculino matriculados em cursos das áreas de Ciências Exatas e da Natureza, Tecnologia e Geociências e Informática da UFPE. A promoção de ações educativas direcionadas para essa população foi fundamentada na hipótese de que estudantes dessas áreas estão inseridos em Centros e/ou Departamentos que oferecem cursos de graduação e pós-graduação que historicamente e majoritariamente apresentam "perfil masculino" (Saboya, 2013; Torres et al., 2017; Maia, 2016). Somado a essa hipótese, a tricomoníase em mais de $70 \%$ dos homens, parceiros sexuais de mulheres diagnosticadas com tricomoníase, apresenta diagnóstico positivo para T. vaginalis, sendo que $77.3 \%$ não manifestam sinais e sintomas clínicos (Sena et al., 2007). Assim, o perfil assintomático que a maioria dos homens infectados apresenta destaca a importância epidemiológica do sexo masculino na transmissão e manutenção da infecção pelo $T$. vaginalis. Neste sentido, além da natureza parasitária do protozoário, os dados epidemiológicos destacam o sexo heterossexual desprotegido como principal via de transmissão do T. vaginalis (Newman et al., 2015; Takemoto et al., 2019). Poucos estudos destacam a transmissão sexual do $T$. vaginalis entre lésbicas e homens transgêneros (Takemoto et al., 2019; Bailey, Farquhar \& Owen, 2004; Carvalho et al., 2013). Logo, falar de tricomoníase é falar em sexualidade e em relações de gênero.

No geral, pesquisas de Educação em Saúde envolvendo o tema IST são direcionadas para a infecção pelo HIV e aplicadas para população escolar e sem distinção de gêneros (da Silva et al., 2020; da Silva Góis et al., 2021). Quando a tricomoníase é reportada em pesquisas de Educação em Saúde há pouca importância clínica e epidemiológica, sendo uma infecção de fácil tratamento e controle. Um cenário que corroborando com a comunidade científica internacional e nacional que classifica a tricomoníase como uma protozoose negligenciada no Projeto Político-Pedagógico, nas ações de Educação em Saúde, clínica médica, políticas públicas de saúde e indústria farmacêutica (Menezes, Frasson \& Tasca, 2016; Muzny, 2018; Takemoto et al., 2019). Além disto, é no sexo feminino que se concentram os estudos com a tricomoníase, especialmente gestantes, profissionais do sexo e mulheres em situação de privação de liberdade.

A ação educativa alcançou 3.162 estudantes de graduação $(n=2.972, ~ 94 \%)$ e pós-graduação $(n=190, \sim 6 \%)$, sendo 1.481 no Centro de Geociência e Tecnologia (CTG), 1.001 no Centro de Ciências Exatas e da Natureza (CCEN) e 680 no Centro de Informática (CIn). O elevado número de estudantes alcançados nas ações, ao longo de três anos de projeto, deve-se à participação ativa, efetiva e voluntária de 60 extensionistas. A cada ação realizada os extensionistas mostravam-se mais próximos com os temas discutidos e ganhavam segurança, desenvoltura e embasamento pedagógico, científico e compromisso social no diálogo com o público-alvo. Assim, evidenciamos e destacamos a importância da extensão universitária, uma vez que possibilita aos graduandos um amplo campo para experimentar, compreender e exercer atividades compatíveis com suas habilidades emocionais e conhecimento adquirido ao longo da sua formação acadêmica, proporcionando assim o desenvolvimento de habilidades e competências que serão requeridas na sua atuação profissional. Deste modo, o presente estudo contribuiu e fortaleceu a formação acadêmica-profissional humanizada dos extensionistas e encontra-se em consonância com a Política Nacional de Educação Popular em Saúde e com as Diretrizes Curriculares Nacionais para os cursos de graduação na área de saúde. Segundo esses apêndices oficiais, a Universidade deve promover ações inovadoras e transformadoras que favoreçam a formação humanizada dos seus estudantes, bem como seu vínculo com a sociedade (Brasil, 2013; Ministério da Educação, 2021).

A idade média, em anos, foi de $21,34 \pm 2,33 ; 19,65 \pm 2,4$ e 23,05 $\pm 3,2$ para os estudantes do CTG, CCEN e CIN, respectivamente. A idade mínima de 16 anos foi registada nos três Centros e a máxima de 45 anos no CTG e 46 anos no CCEN e CIN. As idades mais elevadas foram reportadas entre alunos da pós-graduação em nível mestrado, doutorado e pós- 
doutorado. Por outro lado, o desvio padrão da média das idades e os valores do primeiro e terceiro quartis evidenciam que a população alcançada foi formada predominantemente por jovens. Segundo o Estatuto da Juventude "jovens" são pessoas entre 15 e 29 anos de idade. Ademais, o Estatuto da Juventude considera que a faixa etária de 18 a 24 anos é a mais condizente com a idade de acesso e de permanência no ensino superior, pois leva em consideração que a idade padrão para conclusão do ensino médio é 17 anos e que um curso de graduação é realizado, em média, durante quatro anos (Brasil, 2010; Brasil 2013).

Antes da ação educativa os extensionistas se apresentavam e explicavam o objetivo da proposta e convidavam para participar. Os estudantes que voluntariamente aceitavam eram questionados se conheciam o que é a tricomoníase, caso a resposta fosse positiva; questionavam o que conheciam sobre a infecção, o agente etiológico e alterações fisiopatológicas para o infectado. A proposta inicial foi entender o conhecimento prévio dos estudantes e assim contextualizar e construir estratégias para contribuir com informações e na construção do conhecimento. Perto da totalidade dos estudantes reportaram desconhecer a tricomoníase e seu agente etiológico e não reconhecia o sexo masculino como agente transmissor da infecção. Os estudantes que reportaram conhecer a infecção declararam ter "ouvido falar do assunto" na escola durante o ensino médio ou em cursos preparatórios para o Exame Nacional do Ensino Médio (ENEM). Nenhum estudante sabia que a tricomoníase é uma parasitose causada pelo T. vaginalis. Esse cenário é preocupante, pois reflete que além da fragilidade e necessidade de (re)orientações de implantação e práticas das Políticas de Educação em Saúde voltada para os jovens, deixa claro que há uma necessidade da tricomoníase ser incluída no conteúdo do programa escolar com a devida importância.

Houve a preocupação em manter a ação educativa dinâmica, pois desejávamos despertar e manter a atenção e o interesse dos estudantes. $\mathrm{O}$ diálogo foi consolidado, mas no início alguns estudantes demostraram timidez. Apesar do elevado número de estudantes alcançados, alguns recusaram em participar da ação, e no geral alegavam não ter tempo pois estavam atrasados para atividades de aula, estágio, monitoria, prova ou que precisavam estudar. As declarações foram espontâneas, uma vez que os extensionistas foram orientados a não questionarem os motivos da recusa. No entanto, esse cenário evidencia que as razões dos estudantes não participarem estavam concentradas em compromissos acadêmicos. Esse contexto é corroboram com estudos que reportam a sobrecarga de atividades acadêmicas no ensino, na pesquisa e extensão que estudantes universitários são submetidos (Moretti \& Hübner, 2017; Lilla, 2017; Graner \& Cerqueira, 2019). Neste certeza e com o objetivo de reduzir esse viés de participação, todas as ações educativas foram realizadas nos intervalos das aulas e/ou entre os turnos acadêmicos. Ademais, acreditamos que a exposição do nosso material, painéis, cartazes, foder, preservativos e lubrificantes possam ter "embaraçado" alguns estudantes, uma vez que falar de tricomoníase é falar em sexualidade e em relações de gênero e valores. Segundo Carvalho e colaboradores (2017), além da baixa idade, tabus, mitos e questões religiosas, sentimentais e de valores morais estão associados a recusa por ações de Educação em Saúde que envolvam a promoção das IST, sexualidade e afetividade. Por outro lado, de forma geral, nosso material despertou a atenção e a curiosidade dos estudantes e do público que circulava próximo, e logo se aproximavam para questionar e participar das atividades (Figura 1). 
Figura 1. Momento da roda de conversa e Stand montados com painéis, bancadas com folders, preservativos, lubrificantes e cartilhas (Universidade Federal de Pernambuco, 2019).
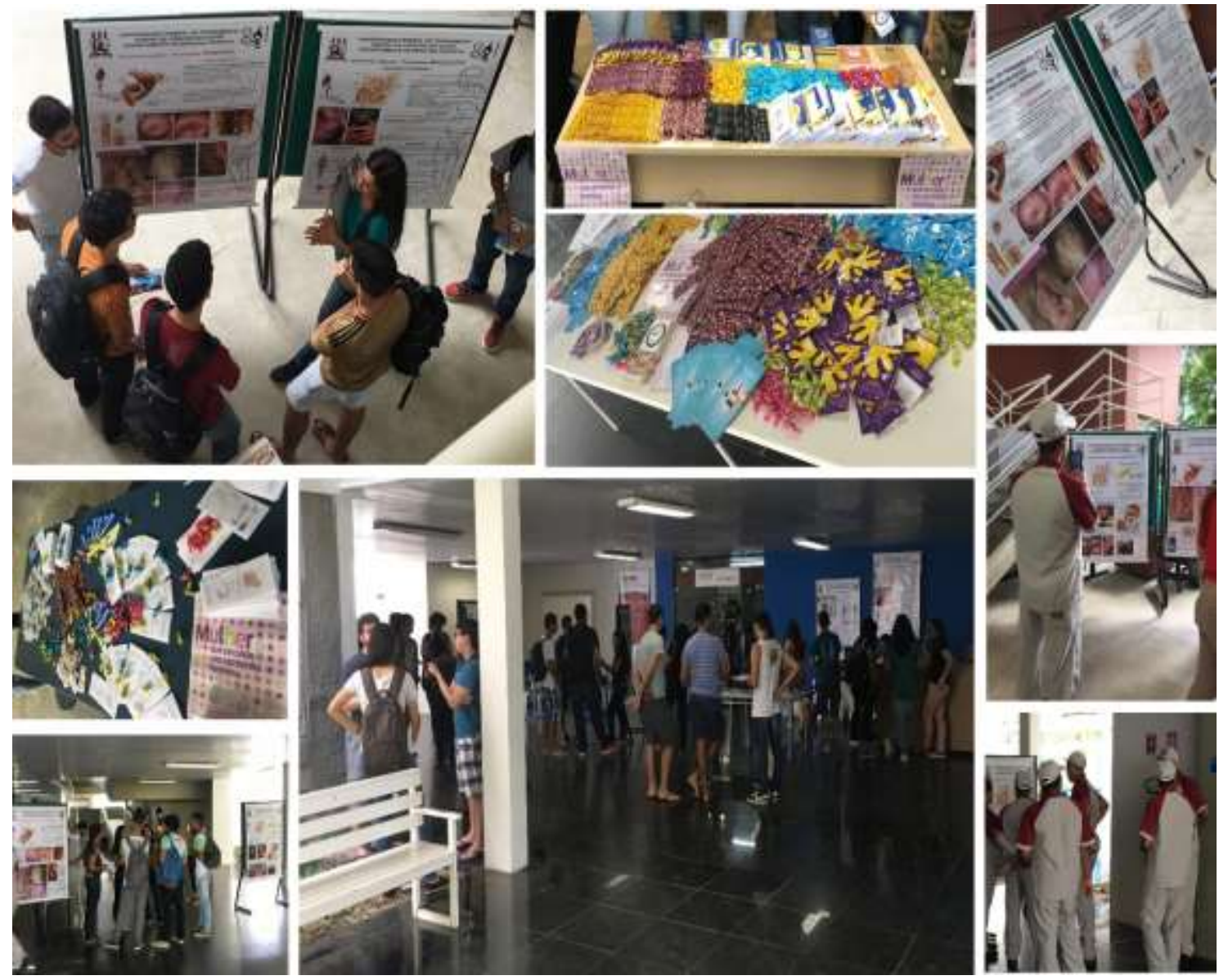

Fonte: Autores.

Após apresentar o projeto e introduzir o tema, o interesse foi surpreendente, especialmente quando mencionávamos os dados epidemiológicos da tricomoníase na população jovem e exploramos imagens das lesões vaginal e peniana, do quadro clínico e a relação do T. vaginalis como agente etiológico facilitador na transmissão e infecção de outras IST, especialmente HIV e a sífilis. Os estudantes ficaram surpreendidos com as profundas alterações anatômicas e fisiológicas nos aparelhos reprodutores feminino e masculino e da correlação do parasitismo com abortos, a infertilidade feminina e masculina, com o câncer de útero e próstata. Neste momento a troca de conhecimento foi enriquecida com questionamentos relacionados como a forma de transmissão, tratamento e prevenção. Na oportunidade, mitos, curiosidades e dúvidas foram esclarecidos e juntos com os estudantes construímos discussões sobre a importância da tricomoníase e da sua prevenção e tratamento. Durante todo o processo empoderamos o público para a atenção na saúde sexual e para o compromisso e responsabilidade frente à saúde sexual da(s) sua(s) parceira(s) sexual(is).

Distribuímos cerca de 3.500 folders sobre tricomoníase e outros 15.000 folhetos e apostilas sobre HIV/AIDS, sífilis e hepatites virais (A, B e C). A utilização de materiais informativos impressos, como cartilhas, manuais e/ou folhetos, é amplamente empregada em ações educativas na área da saúde (Nascimento et al., 2015). Ações de Educação em Saúde são de responsabilidade das profissões pertencentes a essa área e, para a sua realização, os recursos didáticos-pedagógicos educativos são importantes, pois facilitam e articulam a mediação dos conteúdos no processo de ensino-aprendizagem. Além disso, os extensionistas puderam vivenciar uma experiência na elaboração e confecção de um material lúdico e rico em informações, mas sem perder a natureza científica da temática. Segundo Nascimento e colaboradores (2015) folder é um instrumento 
facilitador, eficaz e importante veículo de comunicação por ser de fácil compreensão, claro e objetivo, além de ser capaz de alcançar um grande número de pessoas em pouco tempo e auxiliar no autocuidado.

Pesquisadores alertam para o início precoce da vida sexual entre os jovens brasileiros. No entanto, o início precoce da vida sexual nem sempre é acompanho de medidas preventivas e de amadurecimento afetivo e cognitivo e que este cenário pode comprometer, parcialmente ou totalmente, o seu projeto de vida. Esses estudos ainda destacam que o jovem do sexo masculino inicia a vida sexual mais cedo que jovens do sexo feminino (Almeida et al., 2017; da Silva Góis et al., 2021; da Silva et al., 2020). Os preservativos peniano e vaginal continuam sendo os métodos mais eficientes para prevenção da tricomoníase e outras IST. No entanto, a frequência do seu uso na primeira e em todas as relações sexuais ainda é considerada baixa (Almeida et al., 2017; Caetano, Leite \& Rosa, 2017). Assim, orientamos sobre a importância e o uso correto do preservativo, e durante as ações distribuímos cerca de 25.000 preservativos peniano (convencionais e teen), 2.000 preservativos vaginal e 40.000 sachês de gel lubrificante íntimo. No geral, os estudantes receberam os materiais impressos, preservativos e gel sem nenhum tipo de embaraço. No entanto, alguns estudantes não aceitaram receber preservativos ou receberam com receio e aparentemente tímidos. Os extensionistas foram orientados a não questionar razões para a recusa e logo continuar a atividade educativa de forma natural. Mas, alguns estudantes expressaram não aceitar o preservativo por não precisar, ter namorada, vergonha de carregar na bolsa e dos pais encontrarem na bolsa ou no quarto. Evidentemente os motivos da recusa sinalizam a importância de programas de educação sexual, especialmente durante os ensinos médio e fundamental, uma vez que os estudantes ingressam no ensino superior cada vez mais jovem e ainda com carência de conhecimento sobre a importância do uso do preservativo. Destacamos também a importância de programas para distribuição de preservativos; ações que devem ser acompanhadas de instruções para seu uso correto e ainda para a conscientização sobre o sexo seguro. Na ação educativa aqui apresentada é possível identificar estigmas em aceitar e/ou portar preservativos. Nossa reflexão é corroborada com Moreira e colaboradores (2018) que reportam a "marginalização e preconceito" na aquisição, em aceite, usar e/ou ter posse de preservativo entre universitários. O Ministério da Saúde do Brasil (2017) orienta que deve-se considerar o homem numa perspectiva relacional de gênero, aí se destacando a importância na saúde e o comportamento de homens adolescentes, uma vez que essa população influencia diretamente a saúde de mulheres adolescentes (Brasil, 2017).

Os extensionistas tiveram a oportunidade de vivenciar a parasitologia em experiências além da sala de aula, livros ou artigos científicos. Segundo Aires e colaboradores (2018), o ensino da parasitologia deve ser crítico e reflexivo, e articulado com a pesquisa e a extensão, em atividades interdisciplinar e transdisciplinar em metodologias que estimulem o graduando para o aprendizado e profissionalismo humanizado. Essa reflexão está de acordo com os estudos de Leoni e Rodrigues (2016). Segundo esses autores, há uma necessidade de mudança na prática pedagógica e a utilização de novas metodologias para que possam emergir melhores condições de aprendizagem.

\section{Considerações Finais}

A vulnerabilidade do homem, no contexto da saúde individual e coletiva e diante dos inúmeros agravos orgânicos, econômicos e sociais que às Infecções Sexualmente Transmissíveis, incluindo diante da tricomoníase, representa um promissor campo para ações de programas e projetos de extensão universitária. Frente aos resultados apresentados é possível concluir que ações de extensão universitária empregando estratégias de Educação em Saúde, fundamentadas na educação conscientizadora e problematizadora, configuram-se elementos transformadores no cuidado à saúde da população de universitários do sexo masculino das áreas de Ciências Exatas e da Natureza, Informática e Geociências e Tecnologia da UFPE, uma vez que houve construção do conhecimento e discussões e reflexões vivenciadas frente à importância da tricomoníase. Certamente, através das ações de Educação em Saúde aqui reportadas, nossos resultados destacam importante contribuição para à saúde da população alcançada, mudança de comportamentos frente a importância do uso correto do preservativo e na responsabilidade 
na saúde sexual de sua(s) parceria(s), resultando na sustentabilidade da vida sexual saudável e segura.

Diante dos resultados, demostramos a importância da prática de ações de Educação em Saúde na extensão universitária, uma vez que permitem aos estudantes de graduação a oportunidade de aplicar o conhecimento adquirido durante sua formação acadêmica; compreendendo um processo de construção de saber amplo através de experiências reais, contextualizadas e interdisciplinares e da importância na relação estabelecida entre a Universidade e a sociedade. Ademais, foi através da extensão que consolidamos a aproximação e troca de conhecimentos e experiências entre professores, extensionistas e população-alvo; contribuindo para a formação de profissional humanizados, críticos e reflexivos. No final, destacamos a Universidade como locu estratégico para promover ações inovadoras e transformadoras em Educação em Saúde que favoreçam a formação humanizada dos seus estudantes, bem como seu vínculo com a sociedade.

\section{Agradecimentos}

Os autores agradecem a colaboração e empenho das coordenações dos Centros de Ciências Exatas e da Natureza, Informática e Geociência e Tecnologia da UFPE e ao apoio financeiro da Pró-reitoria de Extensão e Cultura da UFPE através do Edital PIBExC para Ação Curricular de Extensão (Acex), ao Conselho Nacional de Desenvolvimento Científico e Tecnológico (CNPq), a Coordenação de Aperfeiçoamento de Pessoal de Nível Superior (CAPES). Fundação de Amparo à Ciência e Tecnologia do Estado de Pernambuco (FACEPE) pela Bolsa de Fixação de Pesquisador a H.D.A. de Araújo (BFP0080-2.08/20). Secretaria Estadual e Municipal de Saúde de Pernambuco e Recife, respectivamente. Agradecemos especialmente a todos os alunos extensionista que contribuíram com a realização deste estudo.

\section{Referências}

Almeida, R. A. A. S., Corrêa, R. D. G. C. F., Rolim, I. L. T. P., Hora, J. M. D., Linard, A. G., Coutinho, N. P. S., \& Oliveira, P. D. S. (2017).

Conhecimento de adolescentes relacionados às doenças sexualmente transmissíveis e gravidez. Revista Brasileira de Enfermagem, $70(5), 1033-1039$.

Bailey, J. V., Farquhar, C., \& Owen, C. (2004). Bacterial vaginosis in lesbians and bisexual women. Sexually transmitted diseases, 31 (11), 691-694.

Brasil. Ministério da Saúde (2010). Departamento de Ações Programáticas Estratégicas: Diretrizes Nacionais para a atenção integral à saúde de adolescentes e jovens na promoção, proteção e recuperação da saúde.

Brasil. (2013). Portaria n 2.761, de 19 de novembro de 2013. Institui a Política Nacional de Educação Popular em Saúde no âmbito do Sistema Único de Saúde-PNEP-SUS. Diário oficial da União.

Brasil. Ministério da Saúde (2017). Proteger e cuidar da saúde de adolescentes na atenção básica. Secretaria de Atenção à Saúde Departamento de Ações Programáticas e Estratégicas.

Caetano, A., Leite, S. Q. M., \& Rosa, C. A. (2017). Educação em saúde na escola: plano de intervenção escolar para debater infecções sexualmente transmissíveis no ensino médio. Experiências em Ensino de Ciências, 12(8), 121-137.

Carvalho, K. E. G., Freitas, N. O., Souza, J. C., Santos, C. P., Barbosa, E. C. S., \& Araújo, E. C. (2014). Adolescência e Sexualidade: Reflexões pela prática da enfermagem em educação em saúde. Rev enferm UFPE online, 8(supl 1), 2522-7.

Carvalho, M. C., \& Sívori, H. F. (2017). Ensino religioso, gênero e sexualidade na política educacional brasileira. Cadernos pagu, (50), e1750117.

Carvalho, P. M. G. D., Nóbrega, B. S. M., Oliveira, J. L., Almeida, R. O., Abdalla, F. T. M., \& Nichiata, L. Y. I. (2013). Prevenção de doenças sexualmente transmissíveis por mulheres homossexuais e bissexuais: estudo descritivo. Online Brazilian Journal of Nursing, 12(4), 931-941.

Chen, B., Lu, Y. N., Wang, H. X., Ma, Q. L., Zhao, X. M., Guo, J. H., \& Chen, P. (2008). Sexual and reproductive health service needs of university/college students: updates from a survey in Shanghai, China. Asian journal of andrology, 10(4), 607-615.

Corrêa, G. C. G., de Campos, I. C. P., \& Almagro, R. C. (2018). Pesquisa-ação: uma abordagem prática de pesquisa qualitativa. Ensaios pedagógicos, 2(1), $62-72$.

da Silva Góis, A. R., Barbosa, P. F. C., Gonçalves, V. H. G. B., da Silva, V. F., da Silva Góis, C. G., de Oliveira, R. C., \& da Silva Abrão, F. M. (2021). Educação em saúde nas escolas: conhecimentos de adolescentes sobre o Vírus da Imunodeficiência Humana. Research, Society and Development, 10(3), e51210313636-e51210313636.

da Silva, N. V. M., da Silva, J. L. L., de Oliveira, M. A., de Azevedo Vellasques, M. A., Resende, J. V. M., \& da Mota, C. P. (2020). Educação em saúde com adolescentes sexualidade e prevenção de IST. Research, Society and Development, 9(8), e107985436-e107985436. 
de Lima Aires, A., da Cruz, C. S., Nascimento-Silva, L. M., \& de Azevedo Albuquerque, M. C. P. (2018). Comércio ambulante de alimentos na universidade: uma questão de segurança alimentar e prevenção de parasitoses intestinais/Food trade in the university: a question of food safety and prevention of intestinal parasites. Saúde e meio ambiente: revista interdisciplinar, 7(1), 20-31.

Esteves Campos, E. F. (2020). Ensino, pesquisa, extensão: Contribuições da pesquisa-ação. Actualidades Investigativas en Educación, $20(1), 533-551$.

Falkenberg, M. B., Mendes, T. D. P. L., Moraes, E. P. D., \& Souza, E. M. D. (2014). Educação em saúde e educação na saúde: conceitos e implicações para a saúde coletiva. Ciência \& Saúde Coletiva, 19, 847-852.

Franco, M. A. S. (2005). Pedagogia da pesquisa-ação. Educação e pesquisa, 31(3), 483-502.

Franco, M. A. S. (2018). Pesquisa-ação e prática docente: possibilidades de descolonização do saber pedagógico. In Pesquisa em educação: a pesquisa-ação em diferentes feições colaborativas, 87-118.

Graner, K. M., \& Cerqueira, A. T. D. A. R. (2019). Revisão integrativa: sofrimento psíquico em estudantes universitários e fatores associados. Ciência \& Saúde Coletiva, 24, 1327-1346.

Leoni, P. A., \& de Andrade Rodrigues, D. C. G. (2016). Utilização de uma oficina como auxílio ao ensino no curso de nutrição. Ensino, Saúde e Ambiente, 9(3).

Lilla, M. (2015). Estresse em estudantes do quarto ano de graduação expostos à realização do trabalho de conclusão de curso.

Maia, M. M. (2016). Limites de gênero e presença feminina nos cursos superiores brasileiros do campo da computação. Cadernos pagu, (46), 223 -244.

Menezes, C. B., Frasson, A. P., \& Tasca, T. (2016). Trichomoniasis-are we giving the deserved attention to the most common non-viral sexually transmitted disease worldwide? Microbial cell, 3(9), 404.

Ministério da Educação. (2021). Diretrizes Curriculares - Cursos de Graduação. Recuperado de http://portal.mec.gov.br/component/content/article?id=12991 Ministério da Saúde (BR). Secretaria de Vigilância em Saúde. Departamento de DST, Aids e Hepatites Virais. (2015). Protocolo Clínico e Diretrizes Terapêuticas para Atenção Integral às Pessoas com Infecções Sexualmente Transmissíveis.

Monceau, G. (2005). Transformar as práticas para conhecê-las: pesquisa-ação e profissionalização docente. Educação e Pesquisa, 31 (3), 467-482.

Moreira, L. R., Dumith, S. C., \& Paludo, S. D. S. (2018). Uso de preservativos na última relação sexual entre universitários: quantos usam e quem são?. Ciência \& Saúde Coletiva, 23, 1255-1266.

Moretti, F. A., \& Hübner, M. M. C. (2017). O estresse e a máquina de moer alunos do ensino superior: vamos repensar nossa política educacional? Revista Psicopedagogia, 34(105), 258-267.

Muzny, C. A. (2018). Why does Trichomonas vaginalis continue to be a "neglected” sexually transmitted infection? Clin Infect Dis, 2;67(2):218-220.

Nascimento, É. A., Tarcia, R. M. L., Magalhães, L. P., Soares, M. A. D. L., Suriano, M. L. F., \& Domenico, E. B. L. D. (2015). Folhetos educativos em saúde: estudo de recepção. Revista da Escola de Enfermagem da USP, 49(3), 432-439.

Newman, L., Rowley, J., Vander Hoorn, S., Wijesooriya, N. S., Unemo, M., Low, N., \& Temmerman, M. (2015). Global estimates of the prevalence and incidence of four curable sexually transmitted infections in 2012 based on systematic review and global reporting. PloS one, 10(12), e0143304.

Pereira, J., Klein, C., \& Meyer, D. E. (2019). PNAISH: uma análise de sua dimensão educativa na perspectiva de gênero. Saúde e Sociedade, $28,132-146$.

Rowley, J., Vander Hoorn, S., Korenromp, E., Low, N., Unemo, M., Abu-Raddad, L. J., \& Taylor, M. M. (2019). Chlamydia, gonorrhoea, trichomoniasis and syphilis: global prevalence and incidence estimates, 2016. Bulletin of the World Health Organization, 97(8), 548.

Saboya, M. C. L. (2013). Relações de gênero, ciência e tecnologia: uma revisão da bibliografia nacional e internacional. Educação, Gestão e Sociedade, 3(12), $1-26$.

Sales, W. B., Caveião, C., Visentin, A., Mocelin, D., da Costa, P. M., \& Simm, E. B. (2016). Comportamento sexual de risco e conhecimento sobre IST/SIDA em universitários da saúde. Revista de enfermagem referência, 4(10), 19-27.

Schwebke, J. R., \& Burgess, D. (2004). Trichomoniasis. Clinical microbiology reviews, 17(4), 794-803.

Sena, A. C., Miller, W. C., Hobbs, M. M., Schwebke, J. R., Leone, P. A., Swygard, H., \& Cohen, M. S. (2007). Trichomonas vaginalis infection in male sexual partners: implications for diagnosis, treatment, and prevention. Clinical infectious diseases, 13-22.

Separavich, M. A., \& Canesqui, A. M. (2013). Saúde do homem e masculinidades na Política Nacional de Atenção Integral à Saúde do Homem: uma revisão bibliográfica. Saúde e Sociedade, 22(2), 415-428.

Sevalho, G. (2012). O" homem dos riscos" e o" homem lento" e a teorização sobre o risco epidemiológico em tempos de globalização. InterfaceComunicação, Saúde, Educação, 16(40), 07-20.

Sousa, J. C. D. O., \& Carvalho, C. R. (2017). Resistência Masculina pela Atenção à Saúde. Revista Científica Multidisciplinar Núcleo do Conhecimento, 7(09), 5-16.

Takemoto, M. L. S., Menezes, M. D. O., Polido, C. B. A., Santos, D. D. S., Leonello, V. M., Magalhães, C. G., \& Knobel, R. (2019). Prevalence of sexually transmitted infections and bacterial vaginosis among lesbian women: systematic review and recommendations to improve care. Cadernos de saude publica, 35, e00118118. 
Research, Society and Development, v. 10, n. 7, e20010715345, 2021

(CC BY 4.0) | ISSN 2525-3409 | DOI: http://dx.doi.org/10.33448/rsd-v10i7.15345

Thiollent, M. J. M. (1986). Metodologia da pesquisa-ação. In Metodologia da pesquisa-ação, 108-108.

Toledo, R. F. D., \& Jacobi, P. R. (2013). Pesquisa-ação e educação: compartilhando princípios na construção de conhecimentos e no fortalecimento comunitário para o enfrentamento de problemas. Educação \& Sociedade, 34(122), 155-173.

Torres, K. B. V., Bernardes, R. M., de Queiros, P. S., Vieira, T. M., Felix, J. C., De Urzedo, A. P. F. M., \& Mendes, T. T. (2017). Inclusao das mulheres nas ciências e tecnologia: Açoes voltadas para a educaçao básica. Expressa Extensão, 22(2), 140-156.

Tripp, D. (2005). Pesquisa-ação: uma introdução metodológica. Educação e pesquisa, 31(3), 443-466.

Vilhena, M. (2013). Sexualidade Masculina do adolescente-Perspectivas Male Sexuality of the adolescent-Perspectives. Adolesc. Saúde (Online), 67-71. 